\title{
Subareolar Dermofibrous Flaps for Correction of Inverted Nipple
}

\author{
FADY R. HANNA, M.Sc.; WALEED Y. EL-SHERPINY, M.D.; SALAH El-DIN A. EL-GOHARY, M.D. and \\ AHMED A. DARWISH, M.D.
}

The Department of General Surgery, Faculty of Medicine, Tanta University, Tanta, Egypt

\begin{abstract}
Background: Inverted nipple is a nipple located on a plane lower than the areola, presents both functional and cosmetic problems. It is a source of repeated irritation and inflammation interferes with nursing and may cause psychologic distress.

Many operative modalities are available for correction; they range from suture based methods to the use of areolar or nipple dermal flaps. This variety of available methods amply reflects the difficulty of achieving a satisfactory outcome. In this study a new technique is adopted, based on the use of two triangular subareolar dermofibrous flaps.
\end{abstract}

Aim: The aim of this study was to assess the use of subareolar dermofibrous flaps for correction of inverted nipple in term of shape and recurrence.

Methods: The study was carried out on 15 inverted nipples in 10 female patients. Every case was subjected to the following: Full history taking, clinical examination including general, breast, axilla, nipple and areola examination. The investigations conducted included laboratory work up and breast mammography with complementary ultrasonography.

Results: The follow-up period after removal of distracter ranged from 6 months to 1 year. During the follow-up period, patient satisfaction was assessed. Good aesthetic results were achieved for $80 \%$ of patients who were very satisfied with the outcome while $20 \%$ were not satisfied because of recurrence. Infection occurred in only 1 patient in the immediate post-operative period that resolved after antibiotic administration. No complications such as pain, temporary sensory disturbance, skin pigmentation or nipple necrosis were recorded in this study.

Conclusions: The described technique is easy, reliable and does not leave visible scars on areolar skin. In particular, it has been found to be effective for treating grade 2 and 3 inverted nipples.

Key Words: Inverted nipple - Correction - Subareolar dermofibrous flaps.

Correspondence to: Dr. Fady R. Hanna, The Department of General Surgery, Faculty of Medicine, Tanta University, Tanta, Egypt

\section{Introduction}

A WOMAN may feel that her nipples are abnormal only because the two nipples appear to be different from each other, either in shape, size or color. It is very common for a woman's breasts to be asymmetrical in shape and size, so also the two nipples may vary slightly in their appearance and in such cases it is not considered as a deformity [1]

\section{Causes of inverted nipple:}

\section{A- True inverted nipple:}

- Congenital Around 10-20\% of all women are born with this condition caused by short ducts or a wide areola muscle [2]

- Acquired as post traumatic with subsequent fat necrosis, post breast surgery, chronic inflammation such as mammary duct ectasia, chronic breast abscess or tuberculosis and Breast cancer involving nipple.

\section{B- Apparent inverted nipple:}

- Breast sagging, drooping or ptosis.

- Gynecomastia.

- Rapid and major weight loss.

\section{Classification of nipple inversion:}

Current classification is according to Han and Hong grading, there are 3 grades of nipple inversion [3]:

- Grade (1): The inverted nipple is easily pulled out, maintains its projection fairly well without traction. Gentle finger pressure around the areola or gently pinching the skin causes the nipple to pop back out.

- Grade (2): The inverted nipple can be pulled out, but not as easily as in Grade 1. After releasing traction, the nipple tends to fall back and invert again. 
- Grade (3): The nipple is severely retracted and inverted. It is difficult to physically force this nipple out and hold it there.

Inverted nipples occurs in about two out of every 100 women, so it is the most important and common abnormality. Inverted nipples are usually evident as a slit or a hole in the breast at the location of the nipple and may be present on one or both sides. Inverted nipples are usually a congenital problem but may be related to scarring from breastfeeding or infection in the ducts or a previous breast surgery [2]

Nipple inversion can cause functional problems such as irritation, rash, discomfort and may prevent the ability to breast-feed [4] .

Several different techniques have been developed and currently are in use for correction of the inverted nipple. The diversity of techniques indicates the lack of a good, sustainable and durable solution for this quite common problem [5]

\section{Aim and objectives:}

The aim of this study was to assess the use of subareolar dermofibrous flaps for correction of inverted nipple in term of shape and recurrence.

\section{Patients and Methods}

After approval from Ethical Committee, an informed consent was obtained from all participants in this study. This study included 15 inverted nipples in 10 female patients. It was carried out in the surgical oncology Unit, General Surgery Department at Tanta University Hospital during 2017.

\section{Inclusion criteria:}

-Women of the age group 18 years or older.

- Women who are having grade 2 or 3 inverted nipple.

-Women who understand the pros and cons of the surgery.

-Women who are having this corrective surgery for the first time.

\section{Exclusion criteria:}

-Women with apparent inverted nipple.

-Women who are having grade 1 inverted nipple.

- Women with breast cancer.

Every patient included in this study was subjected to the following: full history taking, clinical examination including general, breast, axilla, nipple and areola examination. The investigations con- ducted included laboratory work up and breast mammography especially those above 35 years old with complementary ultrasonography.

\section{Surgical procedure:}

\section{-Pre-operative preparation:}

An informed consent from legal guardian was obtained before surgery and after full explanation of the procedure and its purposes. A single dose of a $1 \mathrm{gm}$ third generation cephalosporin was administrated 1 hour before operation.

\section{Operative details:}

Under general anesthesia, the nipple is pulled out using two 3-0 vicryl traction sutures. Two triangular flaps are designed on the areola at the 3 and 9 o'clock positions. The base of each flap is about $10 \mathrm{~mm}$ long and located at the nipple base; their sides are also about $10 \mathrm{~mm}$ long. The bases of the flaps are incised in the dermal layer and then the subdermal layer is undermined over the triangular flaps. The triangular dermofibrous flaps are then elevated and a tunnel is made under the nipple from each flap base. The fibrous bands that constrict the base of the nipple were freed through blunt dissection and a vertical spreading technique parallel to the ducts, initially helping to restore nipple projection. The ducts were visually identified as tubular nonvascular structures, larger and of different consistency than nerves. They did not resemble scar tissue. When necessary, selective ductal division was performed to achieve complete eversion with normal projection until the nipple turns outward without traction. The tip of each flap is then turned down, pulled out through the tunnel and sutured at the base of the opposite flap using 3-0 vicryl. The subcutaneous tissues of both incisions are sutured in order to shrink the nipple base and sustain the normal appearance of nipple using 3-0 vicryl and the areolar skin is closed to the nipple base using 3-0 vicryl sutures, without tension by minimal undermining.

An external retractor was designed in the first 4 cases using a glass rod placed through the tunnel under the nipple for 7 days to maintain the nipple in an overcorrected position however it was not so effective therefore we used the distal end of 5 or $10 \mathrm{ml}$ disposable syringe with an inner diameter of 1 or $1.5 \mathrm{~cm}$ according to the basal diameter of the patient's nipple, the length was $1.3-1.5 \mathrm{~cm}$. A syringe needle with a diameter of $1 \mathrm{~mm}$ was used as a guide. A 2/0 silk stitch was crossed through the nipple base and fixed over the syringe needle. The height of the elastic frame helps to keep the nipple projected. The supporting frame must be 
kept in place 7-14 days during which the fibrous scar tissue would be developed under the released nipple. A cylindrical dressing of cotton gauze and paper tape is applied.

$\mathbf{A}$

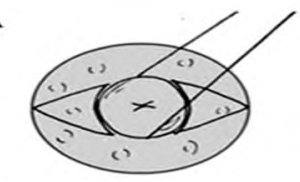

B

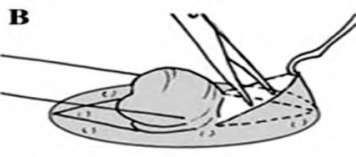

C

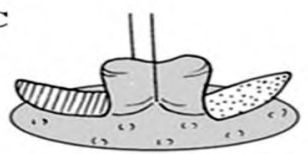

D

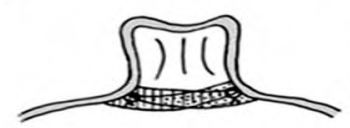

E

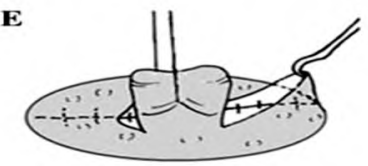

$\mathbf{F}$

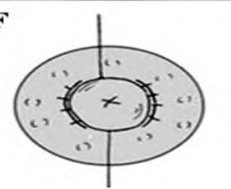

Fig. (1): Schematic drawings and intraoperative views of the procedure.
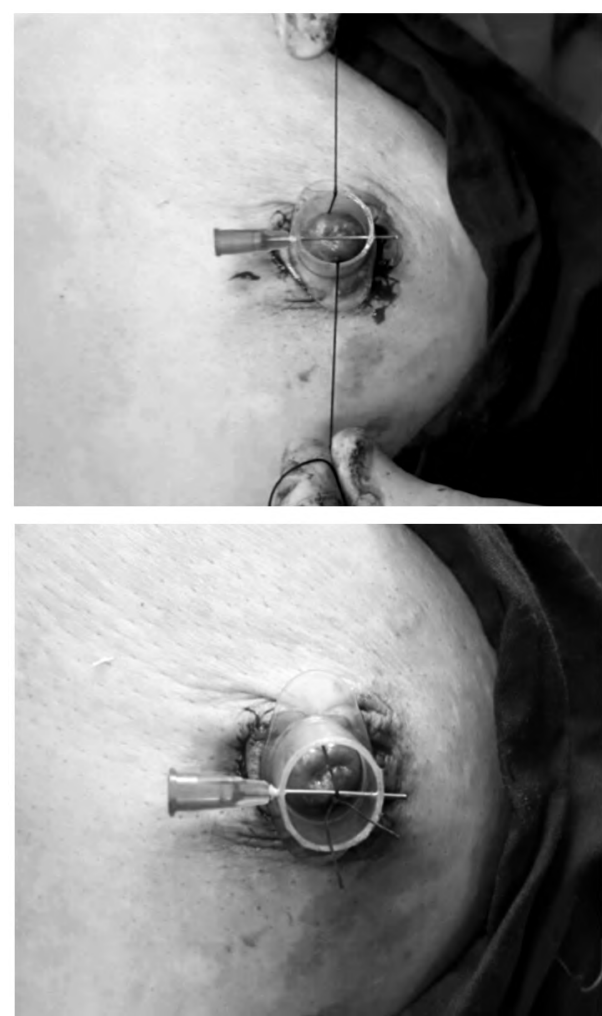

Fig. (2): Applying external retractor using distal end of plastic syringe.

\section{- Post-operative details:}

The patient was given oral antibiotics/12h for 5 days. External retractor was maintained for 7 to 14 days, depending on the degree of retraction. If the nipple retracted easily, traction duration was 7 days (grade 2); if it was densely fibrotic, the retractor was maintained for 14 days (grade 3 ). If there was any sign of vascular compromise, the retractor was removed.

\section{Results}

Once data was collected, a code sheet was developed. Organization, tabulation, presentation and analysis of data were performed by using SPSS V21 of IBM, USA (Statistical Package for Social Studies Version 21.

Numerical data (age) was presented as median, standard deviation and interquartile range as it was not normally distributed (non-parametric).

\section{The Median (Md):}

It is the value that divides the series into two equal groups after all values have been ordered so that half of the values are greater than and half are less than the median.

The order of the value of the median if the number of the values is

$$
\text { odd }=\frac{N+1}{2}
$$

\section{The Interquartile Range (IQR):}

It is a frequently used measure based on quartiles. IQR gives the range of the middle $50 \%$ of the observed values.

\section{The standard deviation:}

The sample standard deviation is the most frequently used measure of variability. It can be considered as a kind of average of the absolute deviations of observed values from the mean of the variable in question.

$$
S D=\sqrt{n-1}^{\sum X^{2} \frac{\left(\sum X\right)^{2}}{n}}
$$

Categorical data was presented as number and percentage.

Mont Carlo Exact Test was used to test the association between recurrence and etiology and 
also between patient satisfaction and complication. The level of significance was adopted at $p<0.05$.

\section{Monte Carlo Exact Test:}

It is a statistical significance test used in the analysis of contingency tables when chi-squared test cannot be applied. It is used to examine the significance of the association between the two kinds of classification.

We found that the number of patients included in this study was 10 patients presented with 15 inverted nipples, their ages ranged from 22 to 45 years. There were 8 patients with negative family history (80\%) and 2 patients with positive family history $(20 \%)$.

Our study showed that 5 patients $(50 \%)$ presented with unilateral inverted nipple and 5 patients (50\%) presented with bilateral inverted nipples. Eleven $(73.3 \%)$ of these nipples were congenital and $4(26.7 \%)$ were acquired. Seven of these inverted nipples (46.7\%) were grade 2 and $8(53.3 \%)$ were grade 3 .

The complaint varied from cosmetic problems in 10 patients $(66.8 \%)$ to breast mass in 3 patients $(20 \%)$ and other problems like itching, bad odor or milky discharge in 1 patient (6.6\%) and recurrence after previous operation in 1 patient $(1 \%)$.

Mammography with complementary US showed the picture of chronic breast abscess in 2 patients $(13.4 \%)$, congenitally short ducts in 11 patients (73.4\%), duct ectasia in 1 patient $(6.6 \%)$ and infected fibrocystic disease in 1 patient (6.6\%).

Twelve patients (80\%) have no complications while the first 2 cases (13.3\%) showed recurrence on one side during first month after operation, they were grade 3 . One of them was operated again with the same technique but using syringe base to develop constant traction of the nipple to avoid recurrence. No recurrence developed till end of following period. Only 1 patient $(6.7 \%)$ developed infection at the site of operation treated with oral antibiotics only. None of the patients experienced nipple necrosis, pain, skin pigmentation or sensory disturbance. Eight patients (80\%) were satisfied with regard to the shape and projection of the corrected nipple while only $2(20 \%)$ were not satisfied because of recurrence.
Table (1): Socio-demographic characteristics of studied patients.

\begin{tabular}{|c|c|c|}
\hline \multirow{2}{*}{ Characteristics } & \multicolumn{2}{|c|}{ Patient $n=10$} \\
\hline & No & $\%$ \\
\hline \multicolumn{3}{|l|}{ Age: } \\
\hline$<40$ years & 9 & 90 \\
\hline$>40$ years & 1 & 10 \\
\hline Median \pm SD & \multicolumn{2}{|c|}{$31.5 \pm 7.2$} \\
\hline Range & \multicolumn{2}{|c|}{$23(22-45)$} \\
\hline \multicolumn{3}{|l|}{ Family history: } \\
\hline Negative & 8 & 80 \\
\hline Positive & 2 & 20 \\
\hline
\end{tabular}

Table (2): Clinical characteristics of the studied patients.

\begin{tabular}{lll}
\hline & \multicolumn{2}{l}{ Patient $(\mathrm{n}=10)$} \\
Characteristics & \multicolumn{2}{c}{ Breasts $(\mathrm{n}=15)$} \\
\cline { 2 - 3 } & No & $\%$ \\
\hline Side: & 5 & 50.0 \\
$\quad$ Unilateral & 5 & 50.0 \\
Bilateral & & \\
Cause: & 11 & 73.3 \\
Congenital & 4 & 26.7 \\
Acquired & & \\
Grading: & 7 & 46.7 \\
Grade 2 & 8 & 53.3 \\
Grade 3 & & \\
Complaint: & 3 & 20.0 \\
Breast mass & 10 & 66.8 \\
Distorted nipple & 1 & 6.6 \\
Itching, bad odour or milky discharge & 1 & 6.6 \\
Recurrence after previous operation & & \\
Mammography with complementary US & & \\
findings: & & \\
Chronic breast abscess & 2 & 13.4 \\
Short ducts & 11 & 73.4 \\
Duct ectasia & 1 & 6.6 \\
Infected fibrocystic disease & 1 & 6.6 \\
\hline
\end{tabular}

Table (3): Post-operative findings in the studied patients.

\begin{tabular}{lll}
\hline & \multicolumn{2}{c}{$\begin{array}{c}\text { Patient }(\mathrm{n}=10) \\
\text { Breasts }(\mathrm{n}=15)\end{array}$} \\
\cline { 2 - 3 } Characteristics & No & $\%$ \\
\hline Complications: & 12 & 80 \\
No & 2 & 13.3 \\
Recurrence unilateral & 1 & 6.7 \\
Infection & 0 & 0 \\
Nipple necrosis & 0 & 0 \\
Scar or skin pigmentation & 0 & 0 \\
Pain & 0 & 0 \\
Hypoesthesia or hyperesthesia & & \\
Patient satisfaction: & & \\
Not Satisfied & 2 & 20 \\
Satisfied & 8 & 80 \\
\hline
\end{tabular}



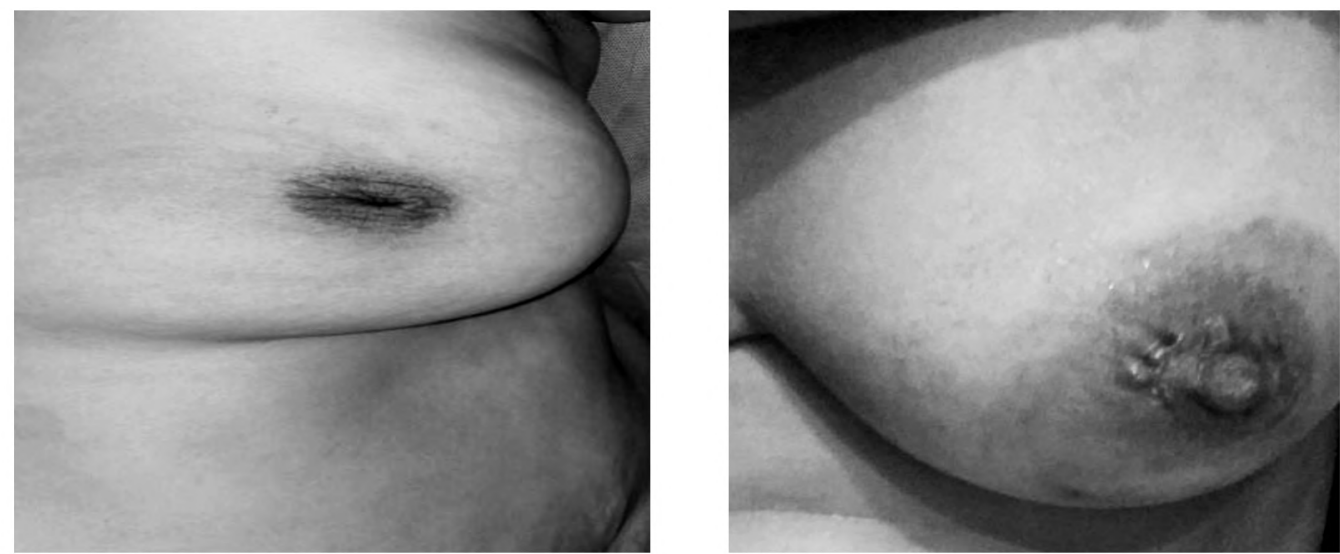

Fig. (3): Corrected inverted nipple 1 week post-operative.
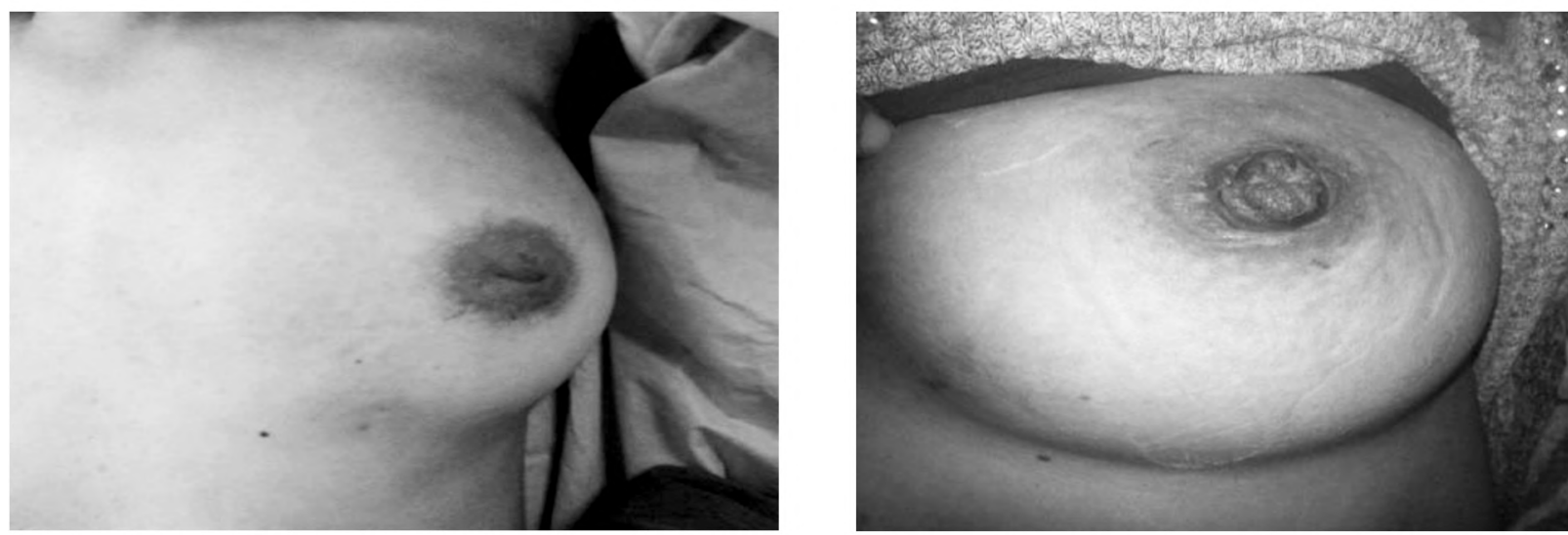

Fig. (4): Corrected inverted nipple 1 month post-operative.
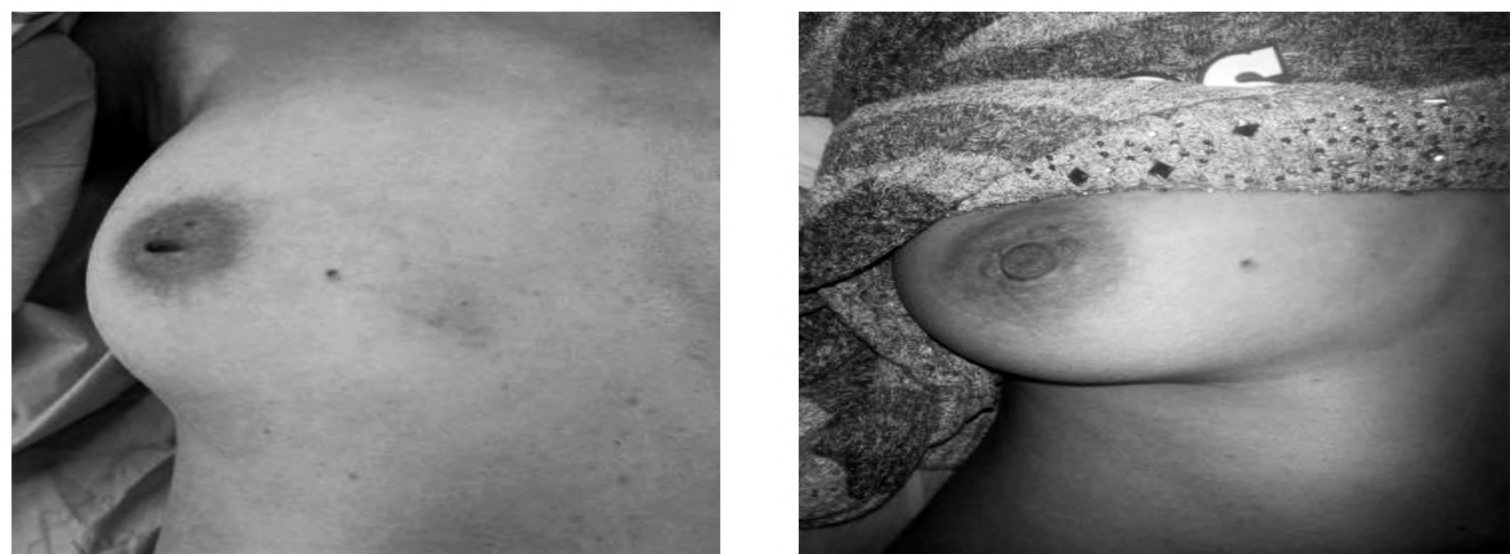

Fig. (5): Corrected inverted nipple 1 year post-operative.

\section{Discussion}

The median age of patients included in this study was 31.5 which is higher than that reported in other studies as Terrill et al., [6] who found that median age of their study was 26 years and $\mathrm{Mu}$ et al., [7] who found that most presenting age of inverted nipple was 22.5 while Gould et al., [8] found that the mean age was 29 years with SD 7.8.
This discrepancy would be attributed to impaired health culture among patients included in this study.

The studied cases showed positive family history in $20 \%$ while it was $36 \%$ in a study performed by Terrill et al., [6]. The small number of the studied cases in the present study may be responsible for the low percentage of positive family history in patients. 
In the present study, five patients $(50 \%)$ presented with unilateral inverted nipple and 5 patients $(50 \%)$ presented with bilateral inverted nipples. Whereas Terrill et al., [6] reported that bilateral involvement was in $69 \%$ of cases and on the left side only in the remaining $31 \%$ of cases, Park HS et al., [9] found that the condition was bilateral in $86.79 \%$ of cases and unilateral in $13.21 \%$, Mu et al., [7] found that $95 \%$ of cases had bilateral inverted nipples and 5\% had unilateral inverted nipples and Gould et al., [8] found that the condition was bilateral in $(87.37 \%)$ of cases and unilateral in $(14.2 \%)$ of cases.

Our study showed that $11(73.3 \%)$ of these nipples were congenital and $4(26.7 \%)$ were acquired whereas Terrill et al., [6] reported that $(66.6 \%)$ of cases had congenital inversion, Park et al., [9] and Karacaoglun, [10] reported that the prevalence of congenital inverted nipple was $3.26 \%$ and $2-10 \%$ respectively.

In the present study, according to the Han and Hong classification [3] seven of these inverted nipples $(46.7 \%)$ were grade 2 and eight $(53.3 \%)$ were Grade 3. While Sakai et al., [11] found that $(9 \%)$ was Grade $1,(34.5 \%)$ was Grade 2 and (56.5\%) was Grade 3.

The results of this study revealed that the main complaint was cosmetic problems in 10 patients (66.8\%) followed by breast mass in 3 patients (20\%), problems like itching, bad odor or milky discharge in 1 patient $(6.6 \%)$ and recurrence after previous operation in 1 patient $(6.6 \%)$. This result coincides with the finding of Zhou et al., [12] who mentioned that the major reason for consultation was to improve the appearance in addition to rehabilitate the function of breast feeding.

In our study, infection was reported in 1 case $(6.7 \%)$ in the immediate postoperative period that resolved after antibiotic administration. This coincides with the finding of Jacques Marin, [13] who noted one case of inflamed submammillary granuloma in the third week post-operatively and Aiache, [14] who noticed post-operative infection in one case.

In the present study, there was no nipple necrosis while in other studies as Sakai et al., [11] who noticed partial nipple necrosis in 4 cases and Huang, [15] who observed sloughing of partial skin of nipple domes in 5 cases as they used 3 periductal dermofibrous flaps that may jeopardize the blood supply to the nipple. That is why in our study no jeopardize of the blood supply of the nipple as only 2 subdermal flaps were used without interruption of the blood supply of the nipple.

In the present study, there were no postoperative pain, nor temporary disturbance (hypoesthesia or hyperesthesia), nor scar or skin pigmentation developed in any case. Other studies as Jacques Marin, [13] encountered slight pain at the tip of the nipple in 3 cases because of overaggressive section of the lactiferous ducts months while Long and Zhao, [16] who used nipple retractor only, there were depigmentation $(2.11 \%)$, areolar ulcer $(2.11 \%)$ and wire dislocation $(1.05 \%)$ and Paraskevas and Sabri, [17] reported that there were pain and some temporary sensory disturbance (hypoesthesia or hyperesthesia) in early post-operative period but it resolved spontaneously within 3-6h.

During the period of follow-up (which ranges from 6 months to 1 year), we only encountered recurrence in 2 nipples (13.3\%) which is comparable with the finding of Sakai et al., [11] who reported recurrence in 5 nipples while Ritz et al., [18] reported that they had to repeat the surgery for one patient with Grade 3 inverted nipples for both nipples 1 year after the primary surgery because of recurrence while, Mu et al., [7] who used only nipple retractor for correction of inverted nipple, recurrent nipple inversion occurred in 2 patients (6.5\%) and Paraskevas and Sabri, [17] encountered 1 unilateral recurrence in a patient that didn't want to put the supporting frame because of summer holidays. The relapse occurred 1 month postoperative and was successfully treated by a second operation using the supporting frame.

The recurrence in the present study could be referred to less extensive dissection of dermofibrous flaps so least number of milk ducts would be injured. One patient with a unilateral recurrence, underwent correction with the same procedure but using syringe base to develop constant traction and scarifying some milk ducts during dissection give the opportunity to elongate the nipple and kept it erect by the flaps. Eight patients (80\%) were satisfied and only $2(20 \%)$ were not satisfied because of recurrence.

\section{Conclusions:}

The inverted nipple still represents a challenge for surgeons. Many surgical methods have been devised to correct inverted nipples of varying severity. These corrective surgical procedures have two basic key points:

1- The adequate release of fibrous bands and lactiferous ducts. 
2- The filling of the defect beneath the nipple.

In addition to these key points, the ideal surgical procedure should be simple, reliable and produce good aesthetic results, a satisfying nipple shape and minimal scars. The technique adopted in this study involved the use of two triangular areolar dermofibrous flaps to treat Grade 2-3 inverted nipples and allowed the inversion to be released and the underlying defect to be filled resulting in push out of the nipple.

Furthermore, because the technique didn't involve areolar skin, it didn't leave visible scars in the areola, and thus it can be used regardless of areola size or obviousness without causing deformity. In addition to that, it can be performed easily and quickly and the technique showed positive sustainable results. Some points should be considered on performing this technique:

- While preparing the dermal flaps, more subcutaneous tissue should be preserved to fill the nipple base. While releasing the nipple base, the blunt dissection should be done gently and carefully to avoid the interruption of the milk ducts. The nipple must be pulled out continuously for at least one week using external retractor as glass rod or distal end of 5 or $10 \mathrm{ml}$ disposable syringe (preferable) with an inner diameter of 1 or $1.5 \mathrm{~cm}$ according to the basal diameter of the patient's nipple, the length was $1.3-1.5 \mathrm{~cm}$. A syringe needle with a diameter of $1 \mathrm{~mm}$ was used as a guide, and a 2/0 Silk stitch was crossed through the nipple base and fixed over the syringe needle. The height of the elastic frame helps to keep the nipple projected. Duration of traction depends on the degree of retraction, if the nipple retracted easily, it was 7 days (Grade 2) but if it was densely fibrotic, the retractor should be maintained for 14 days (Grade 3). If there was any sign of vascular compromise, the retractor was removed.

\section{Acknowledgments:}

This research was carried out without funding.

\section{Conflicts of interest:}

No conflicts of interest declared.

\section{Authors' contributions:}

All authors had equal role in design, work, statistical analysis and manuscript writing.

\section{References}

1- BIBBO M. and HANAU C.: Normal Development and Anomalies. In Tavassoli FA. Pathology of the breast, $2^{\text {nd }}$ ed. Appleton \& Lange Stamford, Connecticut, Hong Kong; Chapter 1: 1-17, 1999.
2- SILENGO M., DEL MONACO A., LINARI A. and LALA R.: Low birthweight, microcephalic malformation syndrome in a 46, XX girl and her 46, XY sister with agonadism: Third report of the Kennerknecht syndrome or autosomal recessive Seckel-like syndrome with previously undescribed genital anomalies, Am. J. Med. Genet.; 1; 111 (3): 275, 2011.

3- HAN S. and HONG Y.: The Inverted Nipple: Its Grading and Surgical Correction; Plast. Reconstr. Surg.; 114 (2): 389-95, 1999.

4- TENG L., WU G.P., SUN X.M., et al.: Coorection of Inverted Nipple an alternative method using continuous elastic outside distraction "Annals of Plastic Surgery"; 54 (2): 120-3, 2005.

5- ALEXANDER J., GRANT A. and CAMPBELL M.: Randomized controlled trial of breast shells and Hoffman's exercises for inverted and non-protractile nipples. British Medical Journal; 18; 304 (6833): 1030-2, 1992.

6- TERRILL P. and STAPLETON M.: The inverted nipple: To cut the ducts or not? British Journal of Plastic Surgery; 44: 372-11, 1991.

7- MU D., LUAN J. and MU L.: A Minimally Invasive Gradual Traction Technique for Inverted Nipple Correction. Aesthetic. Plast. Surg.; 36 (5): 1151-4, 2012.

8- GOULD D., NADEAU M. and MACIAS L.: Inverted nipple repair revisited: A 7-year experience. Aesthet. Surg. J.; 35 (2): 15664, 2015.

9- PARK H., YOON C. and KIM H.: The prevalence of congenital inverted nipple. Aesthetic. Plast. Surg.; 23 (2): 144-6, 1999.

10- KARACAOGLU E.: Correction of Recurrent Grade III Inverted Nipple with Antenna Dermoadipose Flap: Case Report. Aesth. Plast. Surg.; 33: 843-8, 2009.

11- SAKAI S., SAKAI Y. and IZAWA H.: A New Surgical Procedure for the Very Severe Inverted Nipple. Aesthetic. Plast. Surg.; 23 (2): 139-43, 1999.

12- ZHOU H., TAN Q. and WU J.: Correction of inverted nipple with bilateral areolar rhomboid dermal flaps. J. Plast. Reconstr. Aesthet. Surg.; 64 (6): e159-61, 2011.

13- JACQUES M.: Inverted Nipple: The New Method of Correction, Aesth. Plast. Surg.; 13: 189-97, 1989.

14- AIACHE A.: Surgical repair of the inverted nipple. Ann. Plast. Surg.; 25 (6): 457-60, 1990.

15- HUANG W.: A new method for correction of inverted nipple with three periductal dermofibrous flaps. Aesthetic. Plast. Surg.; 27: 301304, 2003.

16- LONG X. and ZHAO R.: Nipple Retractor to Correct Inverted Nipples. Breast Care (Basel); 6 (6): 463-5, 2011.

17- PARASKEVAS A. and SABRI E.: A simple and easy technique to correct inverted nipple deformities. Eur. J. Plast. Surg.; 35: 759-61, 2012.

18-RITZ M., SILFEN R. and MORGAN D.: Simple technique for inverted nipple correction. Aesthetic. Plast. Surg.; 29 (1): 24-7, 2005. 


\section{السديلات الآدمية تحت الهاله \\ التصليح الحلمة الأدمية المقلوبة الهالة}

إن عيوب حلمة الثدى يمكن آن تسبب إحراج شديد بين السيدات، بالرغم من آن هذه العيوب يمكن آن تسبب مشاكل

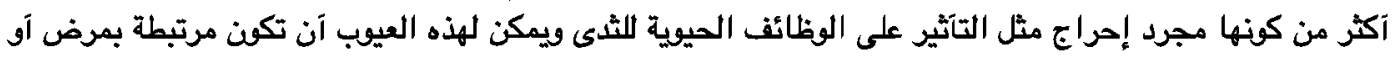

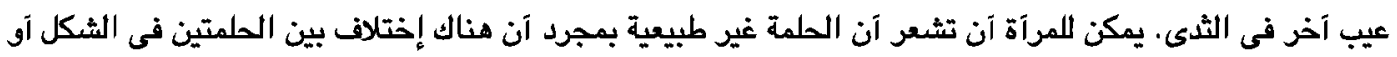

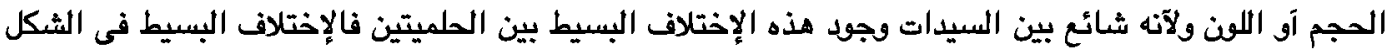

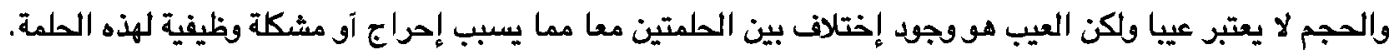

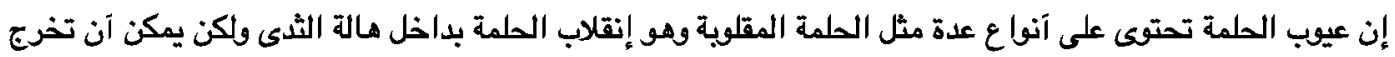

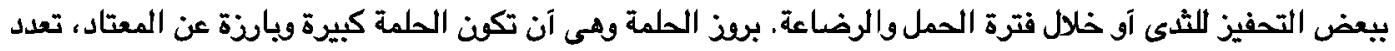

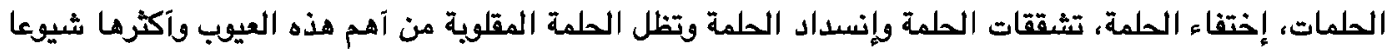

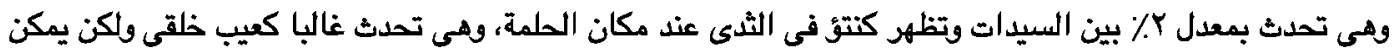

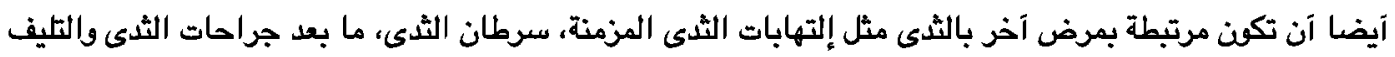

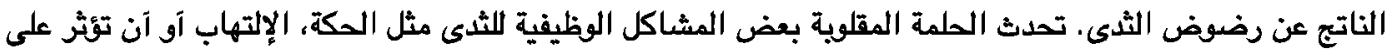

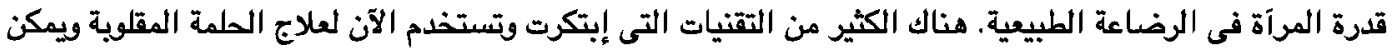

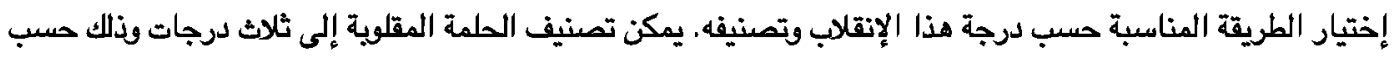
إمكانية عودتها لوضعها الطبيعى ودرجة التليف وما نتج عنها من تلف فى الآنابيب الناقلة لللبن. 